\title{
Silvia Valero*
}

\section{Descentramiento del sujeto en la narrativa de migraciones colombiana ${ }^{1}$}

\begin{abstract}
Resumen: Los movimientos migratorios desde el campo a la ciudad llevaron al crítico Antonio Cornejo Polar a establecer la categoría literaria de sujeto migrante para dar cuenta de un proceso por el cual el sujeto va conformando un discurso descentrado y múltiple, que traduce una biculturalidad con elementos que, si bien son antagónicos, no se resuelven sintéticamente.

A partir de aquí, se analiza la posibilidad de extender los alcances de dicha categoría a los sujetos de las diferentes migraciones en, desde y hacia Colombia, y que la literatura retoma como parte de un proceso que tiene proyección latinoamericana.

En este sentido, este trabajo es parte de una investigación literaria más amplia que analiza las construcciones y reconstrucciones de identidad de aquellos migrantes, latinoamericanos y caribeños que, sobredeterminados por cuestiones de índole política y económica, abandonan sus tierras engrosando la nómina de desterrados.
\end{abstract}

Palabras clave: Sujeto migrante, identidad, migraciones, discurso múltiple.

Abstract: By studying migratory movements of people from country to cities, Antonio Cornejo Polar, proposes the "migrant subject" as a literary category that states the discursive process of the subject. This category becomes useful to explain the characteristics of these discursive constructions: multiplicity, decentralization, and biculturality, antagonistic elements that do not confound themselves synthetically.

From this point, it is possible to extend the use of the category in order to study the subjects of different migration movements in, from and to Colombia, in the literary discourse of Latin America.

In this sense, the whole is a part of a wide research in literature dialing with the construction and reconstruction of identity. This is done in conjunction with the analysis of the economic and political reasons for migration and the impact that this has to do with the linguistic identity of the groups.

Keywords: Migratory subject, identity, migrations, multiple speech.

La historiadora argentina Alcira Argumedo manifiesta que "el pensamiento crítico parte del señalamiento de una crisis del conocimiento que se manifiesta en una antinomia sin solución que emane de ella misma" (Argumedo, 2002:186).
* Universidad Nacional de Córdoba (Argentina), Pontificia Universidad Javeriana.

1 Mi especial agradecimiento al doctor y crítico peruano Raúl Bueno Chávez, quien leyó una primera versión de este trabajo y me señaló algunos aspectos que me fueron de total utilidad para el desarrollo final. 
Esta reflexión me sirve como apoyo para introducir un tema que se agenda en la década del setenta, como parte de lo que luego se apuntaría como "descolonización del conocimiento"2: la heterogeneidad cultural de América Latina. Así, podemos afirmar que el pensamiento crítico sobre este tema (y otras categorías cercanas como hibridez, fagocitación, transculturación, etc.) en América Latina, desarrollado por el peruano Antonio Cornejo Polar, el uruguayo Ángel Rama, el brasileño Antonio Cándido, entre otros, surge frente a la contradicción que supone una teoría homogeneizadora de la cultura nacional (la "comunidad imaginada", de Benedict Anderson), en oposición a una realidad heterogénea que desborda los límites de la pretendida "unidad"3. Esas políticas hegemónicas han elaborado diseños de naciones en las que una ficticia "unidad" hacía alarde de identidades ontológicamente estables y en una "armónica" convivencia, tal como expresa Antonio Cornejo Polar al hablar del mestizaje. Frente a esto, otro crítico peruano, Raúl Bueno Chávez, reflexiona:

En contraste con las otras categorías como transculturación, mestizaje, diversidad, alternatividad o hibridez, que aluden a procesos meramente culturales o raciales, el concepto de heterogeneidad refiere a los procesos históricos que arraigan en la base misma de las diferencias sociales, culturales, literarias, etc., de la

2 Con respecto a este controvertido tema, apunta Zulma Palermo: "Entiendo que este campo de estudio viene a proponerse como una forma de resistencia académica a los discursos hegemónicos de la institución que sigue sosteniendo una actitud 'subdesarrollante' para con las formaciones más débiles de América Latina. Dicha incidencia se pone de manifiesto no sólo en la actual hegemonía lingüística, sino en el traslapamiento de categorías, 'metáforas', cuyos desplazamientos semánticos conllevan importantes desviaciones metodológicas y aun teóricas" (Palermo, 2002:36).

3 Mientras que el concepto de "unidad" nos remite a las concepciones homegeneizadoras, que ignora las variedades propias del complejo socio-cultural, la de "totalidad" da cuenta de la circulación de esa diversidad en coexistencia temporal, y en franca contradicción. realidad latinoamericana. Incluso, en la base de las diferencias culturales y raciales que funcionan como establecedoras de clases de América Latina: el indio, el negro, el mestizo (Bueno, 1996:21).

En muchos casos, la novela cumplió un papel de servidora de dichos proyectos homogeneizadores al privilegiar aspectos estructurales (discursos, personajes, representación) tendientes a crear un imaginario colectivo indiferente a las variedades existentes.

Sin embargo, los encuentros o choques de culturas hablan conjuntamente de diferencias y escisiones histórica y socialmente producidas, y de las posibilidades e imposibilidades del contacto o el intercambio entre esas diferencias que no descansan en "esencias" ni definen entidades estáticas, sino que delinean espacios socioculturales y temporalidades dotados de características y movimientos propios. De allí que, en muchos casos, la literatura deja ver que debajo del discurso o la enunciación monologante hay fuerzas de quiebre que responden a otra matriz, y cuyo ocultamiento absoluto es imposible (aunque en los procesos de mestizaje, entendido éste desde la acepción que da Antonio Cornejo Polar, la tensión se resuelve siempre con la superioridad en el orden del poder de un miembro sobre el otro). La pretendida univocidad, la intentada hegemonía lingüística, se pierde al bucear en la escritura.

\section{Ciudad/heterogeneidad/sujeto migrante}

Al hablar de la heterogeneidad cultural de América Latina, debemos pensar un mapa cultural cruzado por dos coordenadas que lo rigen:

1. Una horizontal, referida al tiempo-espacio en el que se desarrollan las diferentes culturas (comunidades indígenas, regiones agropecuarias, ciudades).

2. Una vertical, reordenadora de la anterior, socialmente hablando, y que tiene que ver con el con- 
texto socioeconómico y sus derivados (pirámide social, tipos de ocupaciones y trabajos, etc.). De este entrecruzamiento surgen las obras literarias que dan cuenta de los dos niveles discursivos a los que hicimos referencia más arriba.

Es por esto que es imposible hablar de heterogeneidad sin hacer referencia a la ciudad y su tratamiento literario. Así, al mismo tiempo que, desde las primeras décadas del siglo XX, intelectuales (críticos, investigadores, escritores) ${ }^{4}$ dan cuenta de la necesidad de una reinterpretación teórica y estética de sus propias regiones culturales, se profundiza la tensión con las culturas metropolitanas modernizadas.

De esta manera, la noción de heterogeneidad cultural tal como ha sido planteada y con todas las tensiones que provoca, se amplía con el abordaje de la construcción del sujeto. Y aquí llegamos a la categoría de "sujeto migrante" creada por Antonio Cornejo Polar, y sobre la cual volveremos para centrar el análisis de los textos seleccionados.

Ahora bien, si existe un elemento que caracterice la dinámica social latinoamericana desde la segunda mitad del siglo XX, es la migración dentro y fuera de las fronteras nacionales. A tal punto modifica la cartografía, no sólo geográfica sino, y sobre todo, cultural e identitaria, que repensar lo que significa hoy ser latinoamericano se vincula, como dice Néstor García Canclini, con “....interpretar la persistencia y los cambios de una existencia conjunta..." (G. Canclini, 2002:12), en cuanto la condición actual de América Latina ya no es su territorio. Aunque las fronteras geopolíticas persistan, los mapas simbólicos se modifican constantemente. Pero el migrar no es un mero movi-

4 Se pueden mencionar como ejemplo, a Oswald o Mario de Andrade en su intento de crear una literatura que profundice la creación de una lengua nacional. Más tarde, los narradores transculturados, al decir de Ángel Rama, quienes, además del fraseo local, apuntan al rescate del imaginario popular de sus propias regiones: José María Arguedas, Gabriel García Márquez, Juan Rulfo. miento físico. El cambio de hábitat arrastra una tensión que afecta el orden vital. El efecto inmediato en el migrante -no viajero/turista ${ }^{5}$ es el choque con una realidad otra que, al mismo tiempo, lo recibe como otro, generalmente usurpador de espacios reales y simbólicos.

La literatura, como práctica social, viene dando cuenta de estas transformaciones a través de lo que se ha llamado "literaturas de la diáspora", referidas básicamente a los desplazamientos de caribeños hacia las metrópolis: Estados Unidos, Inglaterra, Francia. La raíz griega de la palabra diáspora (sperein) significa tanto "sembrar" como "esparcir", por lo que etimológicamente contiene a la vez el sentido de afincamiento y el de desarraigo. Si bien originalmente el término tenía una connotación bíblica, fue a partir de los sesenta que adquirió su acepción actual, según apunta Torres-Saillant, apoyándose en el académico Khachig Tölölyan, director de Diáspora: A journal of transnational studies. Debido a una serie de acontecimientos históricos y desarrollos culturales, en las últimas décadas el concepto de diáspora ha experimentado una expansión significativa, llegando a cubrir las más recientes comunidades que han sufrido dispersión. Es decir, se extiende a todos los grupos contemporáneos que muestren, en una tierra adoptiva, los recursos materiales, la estructura sociopolítica y los incentivos discursivos para representarse a sí mismos como diásporas ${ }^{6}$.

En relación con la problemática de las migraciones, Cornejo Polar, como ya adelantamos, atendiendo a las mismas dentro de las frontera de su país, y a partir de la lectura de Los ríos profundos de José María Arguedas, establece, en la década del noventa, la categoría literaria de "sujeto

5 Según Raúl Bueno, el sujeto viajero observa y presenta el mundo y sus diferencias sin internalizar los debates, ni asumir personalmente los nuevos ejes culturales como necesarios recursos de vida.

6 Silvio Torres-Saillant, El retorno de las yolas. Ensayos sobre diáspora, democracia y dominicanidad. República Dominicana: Editora Manatí, 1999. 
migrante". Si bien centra su estudio en los desplazamientos del campo a la ciudad, considera que este sujeto surgido del fenómeno de las migraciones permitiría leer importantes segmentos de la literatura latinoamericana; especialmente, dice, "los que están definidos por su radical heterogeneidad" (C. Polar, 1996:383). Es que en este caso, la heterogeneidad" también forma parte de la "configuración interna" de cada una de las instancias del proceso de producción literaria (emisor, receptor, código, referente, mensaje) haciéndolas "dispersas, quebradizas, inestables, contradictorias y heteróclitas dentro de sus propios límites" (C. Polar, 1994:16-17).

Dentro de este marco, el sujeto migrante se conforma internamente heterogéneo, como resultado del acto de migrar, ya que la necesidad lo hace fagocitar -al decir de Kusch-culturas y lenguas, sin diluir sus diferencias y problemas, sino acentuándolas. Rompe con la noción de sujeto romántico, jerárquico y autónomo, para dar cuenta de las contradicciones internas que se denuncian, básicamente, en el discurso del migrante que

es radicalmente descentrado, en cuanto se construye alrededor de ejes varios y asimétricos, de alguna manera incompatibles y contradictorios de un modo no dialéctico ${ }^{8}$.(...) imagino que el allá y el aquí, que son también el ayer y el hoy, refuerzan su aptitud enunciativa y pueden tramar narrativas bifrontes (...) considero que el desplazamiento migratorio duplica (o

7 La heterogeneidad se nos revela anclada en la interacción sociedad, cultura e historia, y refiere a los procesos históricos que arraigan en la base misma de las diferencia sociales, culturales, literarias, etc., de la realidad latinoamericana. Por eso, se hablará de una "heterogeneidad de base", de la cual derivará la "heterogeneidad secundaria" que es la referida a los procesos culturales.

8 Cornejo Polar opone la categoría de sujeto migrante a la de mestizaje cultural en cuanto aquél no busca una síntesis armónica. Cabe aclarar que para el crítico peruano, el mestizaje en ningún sentido puede ser armónico, en la medida en que siempre hay un ceder poder de la cultura dominada a la dominada. más) el territorio del sujeto y le ofrece o lo condena a hablar desde más de un lugar. Es un discurso doble o múltiplemente situado (C. Polar, 1996: 841).

Asumiendo estas reflexiones y retomando las palabras de Raúl Bueno -en cuanto a la posibilidad de evolución de algunos conceptos, pero siempre dentro del espíritu de sus forjadores-, creo posible hacer caminar la categoría de sujeto migrante, focalizando la atención en las narrativas surgidas como representaciones de las diversas migraciones en, desde y hacia Colombia, como efectos de la violencia política y económica.

\section{El "sujeto migrante" en la narrativa colom- biana}

Mucho es lo que se ha escrito sobre esta problemática de los desplazamientos internos desde la sociología, la antropología, la politología, etc., por lo cual no creo necesario ubicar el tema desde esos aspectos. Sin embargo, muy poco es lo que se ha dicho acerca de la literatura centrada en este tópico. A excepción del trabajo que Luz Mary Giraldo ${ }^{9}$ viene realizando desde hace tiempo, no se conoce otro estudio sistemático de investigación literaria. Es por eso que veo posible acercar estos textos a la crítica literaria latinoamericana señalada, para comprobar que es entre la persistencia y los cambios, la tradición y lo nuevo, el allá y el aquí, el ayer y el hoy, que se va conformando la subjetividad de los desplazados.

Ahora bien, esta proyección de la categoría nos permite no sólo abordar aquellas obras cuyos personajes se mueven dentro de las fronteras nacio-

9 Véase el artículo "Escrituras del desplazamiento en la narrativa colombiana", en AA.VV., "Desplazamiento". Palimpsesto No 2. Revista de la Facultad de Ciencias Humanas de la Universidad Nacional de Colombia, 2002, e "Inmigrantes y desplazados en la narrativa colombiana contemporánea", en Universitas Humanistica, 53: XXIX (2002:15-25). 
nales, sino también aquellas cuyos sujetos, luego de emigrar de su país de origen y poseyendo una identidad cultural que los significa, regresan a su tierra y se encuentran con que deben convivir con otro espacio, donde los códigos sociales y culturales ya no sólo no son los mismos, sino que, además, revelan diferentes miradas del mundo.

Un tercera situación, que responde a lo que ya se habló acerca de la diáspora, es la narrativa que da cuenta de sujetos con una necesidad de buscar futuro lejos del país, o, como dice García Canclini, "latinoamericanos buscando lugar en este siglo".

\section{Del equilibrio al movimiento: "Somos una familia de desplazados..."}

"En el campo tengo miedo, en la ciudad tengo hambre"

(pintura en una pared del centro de Bogotá).

Los textos que tratan la migración, interna nos dan la posibilidad de atender al proceso de conformación de las subjetividades durante la migración y posteriormente a ella, ya instalados en los lugares receptores. Los que llegan a las grandes ciudades son, parafraseando a Julio Noriega ${ }^{10}$, los que han sobrevivido a las dos caras de la muerte: la inacabable guerra civil colombiana y la migración desde las selvas, los Andes, la costa.

Si bien en ninguno de los textos por tratar se especifica si los desplazados pertenecen a algún grupo étnico, es sabido que, en la realidad, la gran mayoría son campesinos, indígenas o afrocolombianos, con culturas regionales muy arraigadas, con economías precapitalistas, para los que salir de la

10 Julio Noriega, "La poética quechua del migrante andino", en Mazzotti y Zevallos (Coord.). Asedios a la heterogeneidad cultural. Libro en homenaje a A. Cornejo Polar. Philadelphia: Asociación Internacional de Peruanistas, 1996, pp. 311-338. tierra donde han hecho su vida y la de sus hijos y asentarse en otras regiones, casi siempre en las grandes ciudades, los introduce no sólo a ellos en un nuevo mundo, sino que la mirada de los demás será siempre hacia un Otro, extraño, forastero, que usurpa espacios.

Los psiquiatras Ricardo Sánchez y Luis E. Jaramillo afirman que

La identidad, vista como el sentido de mismidad y de continuidad, está determinada, entre otros elementos, por el papel social que se desempeña, por las responsabilidades que se asignan, por el sentido de pertenencia a un grupo familiar $y$ social, y por las posesiones materiales; elementos que se ven afectados por el proceso de desplazamiento y que obligan a cambiar las funciones como ser social... (Sánchez y Jaramillo, 1999:85).

De aquí es interesante destacar el vínculo con la noción de descentramiento del sujeto que desde la crítica literaria desarrolla Cornejo Polar, y que, como ya se ha visto, tiene su máxima expresión en el discurso proliferante y múltiple.

Lamentablemente, los narradores -empíricos, no dan cuenta, en la literatura del desplazamiento, de los rasgos lingüísticos de los desplazados según la zona de donde provengan, elemento que sería de gran operatividad en cuanto el habla es la primera manifestación de la diferencia. Por otro lado, entiendo como dicente de la ausencia de un contacto real con esa Colombia subterránea, el no captar desde lo letrado la importancia de lenguas propias que darían cuenta de una identidad otra, agudamente viva en el siglo XXI, en un país donde conviven, actualmente, y hasta que los actores armados lo permitan, sesenta y cinco lenguas habladas por ochenta y cuatro pueblos indígenas. En este sentido, creo que perdemos posibilidades en el análisis de la construcción del sujeto, pero también pierde el texto una riqueza narrativa posible. 


\section{1 "Nadanostra" $"$ : entre la nada y el deambular incierto}

Si bien existen otros relatos en los que se nos aparece más patente la tensión producida en los sujetos cuya identidad está partida entre el campo de ayer y la ciudad de hoy, la elección de "Nadanostra", de Roberto Burgos Cantor, un relato recopilado en el libro Lugares ajenos. Relatos del desplazamiento, se debe a que se nos narra la historia en el momento mismo de la migración. Esto contribuye al objetivo de este trabajo que es el de echar a andar la categoría de sujeto migrante y tomarlo, así, cuando todavía no se ha establecido en su nuevo aquí y ahora.

La historia comienza cuando el narrador y un poeta reconocido en la comunidad letrada bogotana se reúnen en la habitación del hotel de este último, luego de caminar por Bogotá y discurrir acerca de los cambios culturales de la ciudad. Una vez en el hotel, llega a sus manos un cuaderno encontrado en una iglesia, después de que un grupo de desplazados fuera expulsado por la policía. Sin transición, la historia que veníamos leyendo se corta y comienza a sonar un relato contenido en ese cuaderno, de cuyo autor todo lo que sabremos es que es un joven desplazado, que sólo ha cursado cinco años de escuela y con cierta capacidad para la escritura.

En el texto se enuncia el presente trágico del deambular de un lado a otro sin rumbo fijo. El discurso es fragmentado, tajante. El narrador elige para contar el momento mismo del desplazamiento, cuando comienza a tomarse conciencia de lo que significa la desterritorialización forzada. Si bien es evidente que el relato llegará tamizado por la perspectiva que da el tiempo, el análisis se complejiza en cuanto los sujetos desplazados no cuen-

11 Todas las citas del cuento corresponden a la siguiente edición: Roberto Burgos Cantor "Nadanostra", en Lugares ajenos. Relatos del desplazamient. Medellín: Fondo Editorial Universidad Eafit, Colección Antorcha y Daga, 2001. tan todavía, en el tiempo diegético, con un acá que los constituya como pertenecientes a un nuevo lugar. Están en una encrucijada entre el allá que ya no es: "Volver. Volver a dónde. Volver a la nada. A nada" (148), y el acá inmediato que es el de la incertidumbre, porque el hoy no da garantías de establecimiento "para siempre". El locus de enunciación, el acá, es San Isidro, el lugar desde donde se embarcaron en el ferry que trasladaría a toda la población desplazada hacia alguna ciudad. Allí el relato transforma el pasado verbal en presente y convierte al ahora en el movimiento mismo del ferry, en un trasladarse entre espacios no existentes. Es el momento del tránsito en que se ahonda la tensión entre la nada del allá y el "no saber qué sigue" del aquí. El ayer es inasible por perdido; el hoy, por inconsistente.

L. M. Giraldo, citando a Bachelard, habla sobre el poder de integración que tiene la casa para los pensamientos, los recuerdos y los sueños, y se pregunta qué pasa entonces cuando se obliga, a través de la fuerza, a abandonarla. La desterritorialización, en el caso de "Nadanostra", no contempla la reterritorialización, es decir que la dinámica quedará inconclusa, porque para volver se deber tener adónde. La esperanza del retorno no está ni siquiera diferida. La raíz se ha desprendido de la tierra y ya no tiene lugar en su mundo. "Yo sé que no hay dónde volver porque no quedó nada." (148). Si "la vida es ese hacer más sueños" (149), como dice el narrador, a ellos los dejan sin ambas manifestaciones vitales, porque el hacer, el criar hijos, el levantar el techo, el sembrar la tierra se corresponde con la casa, con un suelo "como punto de apoyo espiritual" (Kusch, 1976:74). La desterritorialización obligada los priva para siempre de eso, del espacio real y del simbólico donde se producía ese hacer. Y como consecuencia directa, se pierden los sueños porque el mañana es incierto: "De nada servía mirarnos, éramos extraños. Forasteros otra vez" (Burgos Cante, 2001).

La inclusión del término "forasteros" nos introduce en la problemática que implica la mirada del 
otro y la autopercepción. Hablar como desplazado presupone el reconocimiento de una marginalidad intrínseca. Es reconocerse como voz de la alteridad. Y el término mismo está marcando la presencia interna, en el sujeto, de dos lugares y dos tiempos, porque desplazarse, en este caso, no sólo implica ir de un lugar a otro, sino la pérdida de los significantes que lo identifican como sujeto y la adquisición de otros. El narrador, en la huida, vuelve varias veces la mirada hacia lo que se deja atrás, como intentando avivar la memoria, que se constituye en un aspecto fundamental del resguardo de su identidad primera en cuanto le han destruido lo que lo significaba. Así, el descentramiento discursivo supone una ruptura forzada con el espacio originario, y a la vez un desajuste con un futuro incierto, en una, seguramente, barriada urbana que le será hostil y en la que deberá reconstruirse subjetivamente. A esta angustia hay que sumarle otros sentimientos que también desempeñarán un papel importante en esa reconstrucción. Es que además del descentramiento en la configuración de la identidad, como efecto de la yuxtaposición de espacios y tiempos, se debe tener en cuenta otra consecuencia de la migración. Mauricio García Durán, coordinador nacional del servicio jesuita a refugiados en Colombia, dice: "Los desplazados, en especial los niños, han sido víctimas de la violencia, y más grave aún, normalmente no tienen muchas posibilidades de elaborar los efectos que ésta ha producido en ellos: dolor, miedo, rabia, deseos de venganza, culpabilidad, minusvaloración, etc.”(Garcia Durán, 1999:17).

En este sentido, "Nadanostra" es elocuente: "El abuelo dijo: nadie restituye nada y después cuando el miedo se acaba a uno le queda el rencor. $Y$ eso no se cura. Como la herida del árbol de lata. No se cierra. Supura. Te pudre" (153). El abuelo, que ha sobrevivido a un desplazamiento anterior, da cuenta de que la fisura provocada por la pérdida no cicatriza.

Aparentemente, la única función de aquellos escritores con cuyo encuentro se inicia la narración, es la de permitir la entrada de este metarre- lato de desplazados. Sin embargo, encuentro que la escritura misma es la que tiene carácter operativo, y es el de conectar ambos mundos: el de los escritores en Bogotá, en una cómoda habitación de hotel, y el del desplazado, cuyo último refugio conocido fue una iglesia. El que llegue el texto escrito a manos de los intelectuales hace de este sujeto migrante un sujeto heterogeneizante, porque traslada, aunque involuntariamente, la conflictividad de sus elementos, propios de su periferia, a los centros de poder. Su triunfo está en que su escritura marginal, hecha, en primera instancia, para sí mismo, obstruye el camino de lo que se nos comenzó a contar, y se expande, con una sintaxis tajante, sintomática del pensamiento de su autor, sin desarrollar más que imágenes sueltas pero antagónicas, representación de los mundos del joven desplazado: el ayer y el allá primeros, originarios, idílicos, colectivos libres, y el hoy y el acá trashumantes, dramáticos, inciertos, porque perder el territorio donde se ha soñado y se ha hecho, es perder la espiritualidad:

Se vuelve a una casa. A unos árboles. A los amigos. A unos niños que parecen ser de todos. Iban a una y otra casa.(...) Daba igual. No era igual: daba alegría. Se hacía unión. Se vuelve a los sueños. Ahora no sueño. Pesadillas, sí. Miedos. Sobresaltos. Volver. Volver a dónde. Volver a la nada. A nada.(...) Sembré plantas y árboles. Los oí crecer. Nada estaba... Esa nada me absorbió. Se metió en mí. Me convertí en ella $(148-149)^{12}$.

Nunca sabremos el nombre del narrador de "Nadanostra". La escritura logró heterogeneizarlo, al hacerlo a la vez sujeto del padecer y del narrar, con lo que el personaje narrador puede objetivar y trasladar su experiencia, es decir, contarla desde dos perspectivas: el que sufrió el desplazamiento y el que testimonia ese padecimiento, tanto el de

12 El destacado es mío. 
la ruptura con el espacio originario como el del rechazo del acá y ahora: "Allá estaba todo. Hasta nosotros. Nosotros creemos estar acá, pero quedamos allá. Nos volvieron nada" (154). Este discurso quebradizo nos está diciendo que la herencia cultural es la que transmite al hombre la continuidad que va más allá de su experiencia individual. Por eso el desarraigo se opone al anhelo de continuidad y estabilidad, y también por eso, el anonimato no significa aquí la pérdida de la identidad personal, del nombre propio, sino, como ya vimos, su multiplicación; significa la asociación de un individuo con una pluralidad de otros nombres y otros individuos concretos que, en esta situación histórica del desplazamiento, da cuenta de su condición migrante.

\section{2 “Ángela" ${ }^{13}$, entre la tierra y los tenis}

“Ángela” es un relato extraído del libro de Alfredo Molano, Desterrados, en el que se reproducen testimonios de desplazados, pero siempre a través de la recreación de los mismos por parte de un mediador. El testimonio de Ángela se produce cuando ya la familia tiene un tiempo de establecida en Bogotá, luego de la huida de Nechí, en el Chocó, la región más pobre de Colombia. El discurso de la niña confronta los dos mundos por los que ha travesado en su corta vida.

Ángela, además de contar sobre su realidad, es dicente de sí misma, en tanto revela su contradicción interna. Como en todos los casos de desplazamiento forzado, se produjo una fractura en su estado de equilibrio vital para dar paso a otro de dinamismo caótico provocado por la irrupción de una fuerza ajena, usurpadora. Entrar en el segundo estado, el del desplazamiento, es, asimismo, pasar al del frío nocturno sólo calmado por el hacinamiento, al del llanto por miedo, casi el mismo de la última

13 Todas las citas corresponden a la edición de Alfredo Molano Desterrados. Colombia: El Áncora Editores, 2001. etapa conviviendo con los paramilitares en su tierra. Por eso todo su relato, mediado por el de la entrevistadora, está estructurado en un constante vaivén entre el allá, el campo, y el acá, la ciudad, en el que el conjunto semántico del primer término está compuesto por la abundancia de comida, la libertad de movimientos -aunque cada vez menor desde la llegada de los paramilitares-, el barro tras las lluvias, la tierra fértil y generosa, la relación con los otros confiable y amistosa: "Allá en el solar de la casa, pegaba todo: ají, tomate, limón, papaya, yuca. Todo nos lo comíamos nosotros y a veces había hasta para los vecinos" (42).

Si del ayer se recuerdan los juegos con su padre, el hoy le impone su ausencia en cuanto "sale a trabajar a las 4 de la mañana y vuelve a las 9 de la noche”. El acá es el del pavimento, la cerrazón y la carencia: “...en Bogotá sólo pruebo carne de res; o mejor hueso de res porque la pulpa es muy cara... Echo de menos la carne de monte, la guatinaja, el armadillo, el pisingo..." (43). Es el lugar de la lástima o la indiferencia en la mirada de los otros. El peligro urbano: los gamines, los ladrones y los carros: "En Nechí no hay gamines, y si alguien va a robar, los vecinos lo sacan a patadas. Aquí no es así. Los gamines andan con navajas y pican a la gente para quitarle la plata" (49). El desarraigo y la nostalgia le ayudan a idealizar un espacio que ya no competía en seguridad a la hora de su partida con su familia. La hostilidad del medio actual le hace olvidar que su papá les “...prohibió volver (al río) porque comenzaron a bajar muertos flotando y no quería que nosotros los viéramos" (40).

En realidad, el pasado mediato que ella quiere recuperar está en todo el discurso condicionando el presente.

Ángela relata que sólo tenía dos mudas de ropa y andaba siempre descalza. Pero la pobreza y las dificultades cuando llovía se veían recompensados en su mundo de niña con la felicidad que da el sentirse libre: "Allá me gustaba andar a pie pelado por el barro y nunca me enfermé; como dicen que uno se enferma por no usar zapatos" (35). 
Será el calzado el elemento alrededor del cual la niña centrará la diferencia entre la vida en el pueblo de provincia, donde el alimento -siempre seguro, por otra parte- dependía de una economía basada en la agricultura, la pesca, y esta nueva vida en la gran ciudad, con frío y privaciones. El vivir descalza, en su relato, es la manifestación semántica de la libertad sin riesgos. Por eso, cuando su padre le envía desde la ciudad un par de zapatos usados, dice "me los quité y llegué a Bogotá con ellos en la mano" (48).

Sin embargo, la vida en la ciudad también tiene sus beneficios, y el recuerdo de la libertad perdida en seguida es superado por la posibilidad concreta de hacer uso de los elementos que le ofrece la modernidad urbana. Ya se ha desprendido de su testimonio que la televisión "que aquí es de colores", ha suplantado su originario universo cultural de juegos al aire libre con los elementos que le daba la naturaleza. Pero además, esta televisión le da la posibilidad de desear elementos de consumo que en su mundo anterior no tenían cabida. Así, ante la promesa de su padre de comprarle unas zapatillas rojas que vio en la pantalla y el deseo del mismo de volver al pueblo, ella afirma: "Pero yo no quiero volver: si volvemos a vivir allá, me quedo sin los tenis rojos que mi papá me prometió" (50). Ángela entra en la dinámica de los deseos que constituyen consumidores universales, aunque no todos tengan la misma oportunidad de realizarse. El ayer, con la pertenencia a su cultura, aseguraba bienes simbólicos que constituían la base de su identidad; hoy el consumo hace trastabillar aquella pertenencia.

Se ha producido, como afirma Raúl Bueno, "la incorporación de la heterogeneidad en el mismo sujeto, como resultado del acto de migrar" (:1) Los dos ejes culturales, la tradición y la modernidad, se encuentran en la esfera íntima de la niña. Como dice Elena Altuna, en el sujeto migrante "pasado y presente se funden en imágenes yuxtapuestas mostrándose en su contraste" (1998:5).

\subsection{La Virgen de los sicarios ${ }^{14}$ : entre la ciudad letrada y la jerga marginal}

Como ejemplo de otra instancia crítica en las relaciones entre centro y periferia surge el narrador de La Virgen de los sicarios.

En este caso se subvierte el proceso anterior del desplazado del campo a la ciudad, para dar cuenta de otra posibilidad de construcción subjetiva del sujeto migrante: es la del descentramiento que se produce en el sujeto al chocar con nuevos espacios sociales, construidos como efecto de las diferentes violencias y migraciones, que tensionan con el imaginario cultural contenido en aquellos que, por diferentes causas, dejaron el país hace muchos años. El texto es un ejemplo más de la representación literaria de los desarreglos sociales que la implantación de una modernidad desigual provoca en algunos países latinoamericanos, y que estimula el surgimiento de sectores sociales que, frente a la inviabilidad determinada por la exclusión, expoliados por un sistema coercitivo, para escapar de la alienación asumen mecanismos de contrahumillación que tienen como dinámica la violencia.

De esta manera, el regreso a la tierra de origen da cuenta de un choque entre un ayer y un hoy, un allá y un aquí, que se profundiza en tanto el primer miembro de ambas oposiciones ya no existe, está sólo en el recuerdo del sujeto. Y es precisamente esa desaparición la que establece la complejización del sujeto migrante en esta historia: es posible hablar de la construcción de un tercer lugar de la migración, ya que además del allá (ayer) y del aquí (ahora), existe un nuevo acá que querría recomponer el antes (anterior a la migración) pero que impone un ahora transformado e indeseable.

El texto abre con una remembranza del Medellín de la juventud de Fernando, el narrador. La mirada

14 Todas las citas de la novela correponden a la edición de Fernando Vallejo, La virgen de los sicarios. Bogotá: Alfaguara, 1994. 
sobre la ciudad no es sobre el Medellín real: es una mirada idílicamente nostálgica: "Había en las afueras de Medellín un pueblo silencioso y apacible llamado Sabaneta. Bien que lo conocí porque allí cerca, (...) transcurrió mi infancia" (7). La elección de adjetivos lo construye cerrado porque ha desaparecido; sin embargo, sigue vivo en la nostalgia, y esto hará que el sujeto migrante sitúe constantemente el nuevo acá en un punto de intersección entre lo ausente y su ansiada reproducción, y el presente rechazado pero inevitable. Por eso, a lo largo de toda la obra encontramos elementos que sobreviven, residuales, que marcan la distancia entre lo que fue y lo que ya no es: "Cuando nos bajamos del taxi (un mimo) estaba remedando a un pobre señor honorable, uno de esos seres antediluvianos, desamparados, que aún quedan en Medellín para recordarnos lo que fuimos y lo que ya no somos más y la magnitud del desastre" (93).

El narrador, quien se había exiliado, en su regreso a su ciudad natal se siente expulsado de su tierra, de su ciudad, al menos de la imagen que él tenía en mente sobre Medellín. Se siente un desterrado de su patria, de la que él soñó utópicamente. Está privado del lugar geográfico y social que lo generó y del cual era parte. Es un desterritorializado en su propio territorio. Busca restablecer las redes de identificación, pero ¿cómo recuperar lo que lo significaba si sólo se halla en su recuerdo?

Jerarquiza los lugares -el aquí y el allá-, y el tiempo -el ayer y el hoy-que hacen posible la identificación del sujeto. En el salto de esa topografía simbólica -en cuanto idílica y de paz-, a la presente, tan real y cruel, el itinerario diario por el interior de Medellín traza el proceso de una pérdida, de una desintegración, individual y colectiva, local y nacional. Aquel sujeto romántico que volvió en busca de su yo primero, en un retorno al punto de partida, se convierte en un sujeto lleno de contradicciones internas y, como dice Cornejo Polar, "más relacional que autosuficiente". En el reverso de la desposesión está la esencia extraviada. Esa esencia perdida -la plenitud, la estabilidad- es lo opuesto a los valores que regulan las posiciones y la circulación del sentido en el texto.

Con esa acepción de la nostalgia que atraviesa la obra, el sujeto se construye casi como un exiliado en su propia tierra. El retorno a ella, a la "patria", es un desencuentro con su querencia. Y esto es lo que le despierta el vómito imparable que hace al texto, compuesto por una suerte de discursos híbridos en cuanto se mezcla la memoria con la reflexión trascendental, el análisis político y social con el didactismo irónico a la hora de traducir el lenguaje de los sicarios. La noción de inviabilidad se proyecta desde Medellín hasta el país entero. El futuro hipotecado de la nación es, en definitiva, el motivo de esta elegía por Colombia.

Fernando regresa a su tierra para vivir tranquilo su último tiempo y luego morir. Sin embargo, encuentra, contrariamente, con un contexto que lo aprisiona. Son las comunas como cárceles, especies de prisión, microcosmos prisionero/carcelero, que proyecta sus cadenas hacia el resto de la ciudad. La dicotomía libertad/opresión ahora está invertida. Pero, en todo caso, todos los sujetos sociales son poseedores de ambos estados. La prisión que la modernidad expulsora creó sobre los barrios más pobres hace que éstos, en un acto de supervivencia, desarrollen armas de libertad que son de presión para los otros sectores sociales: "La lucha implacable es a muerte, esta guerra no deja heridos porque después se nos vuelven culebras sueltas. (...) Estos barrios cuando los fundaron eran, como se dice, 'barrios de puertas abiertas'. Ya nunca más” (82-83).

Ahora bien, además del choque emocional que provoca en Fernando el encuentro con este Medellín-Medallo-Metrallo también produce un impacto de la experiencia sobre su propia identidad. La emergencia de esos nuevos sujetos sociales que constituyen los sicarios marcan el límite entre el ayer y el hoy. Ellos forman parte de dos culturas: una tradicional, religiosa, y otra moderna. El narrador reconoce como propia la primera parte de ese 
sujeto, ya de por sí heterogéneo: el "nosotros" de "nuestra" fe católica y "nuestra" vocación reproductora establece la autoinclusión del narrador en la cultura antioqueña, campesina y cristiana. Sin embargo, esa religiosidad de antes, en la que se oraba para el "buen morir", y con la que él se identifica al recordar las procesiones de su niñez ya no existe, y ha dejado su lugar a una actual expresión de fe en la que se reza para el "buen matar". A la tensión provocada en Fernando por la búsqueda de "lo que fuimos y ya nos somos", se le suma el tener que sobrellevar la otra parte de la identidad del sicario, la moderna, que impactará sobre la suya. Y, a la inversa de lo que sucede con Ernesto, en Los ríos profundos, el choque se produce entre su cultura letrada que lo identifica con una autopercepción antagónica a la oralidad de los sicarios. Lo que se consideraba, en el pasado, cultura letrada (que era la única legítima, por lo menos para los letrados), ya no organiza la jerarquía de las culturas y las subculturas. Pero esa cultura oral trasunta una visión del mundo que se opone a la que él evoca como la de su niñez. Con respecto a esto, dice José Cardona López:

Sus virtudes de gramático, las que a la vez representan la tradición de un orden idiomático en un país que se ha preciado de ostentar el descabellado engaño ideológico de hablar el mejor español del mundo, son perforadas por vocablos y giros de una jerga nacida en el fragor inclemente de la calle y la vida dura que ocasiona la marginalidad social (1996:397).

Asimismo, Fernando se vale de ese discurso durante toda su enunciación, para construir un sicario que es una metonimia del país marcado por la muerte, el robo, la usurpación.

Aunque resulte redundante y obvio, no es posible hablar de la narrativa del sicariato sin abordar, aunque sea tangencialmente, la problemática de la modernidad. El tiempo acelerado pero sentido como sin-sentido en La Virgen de los sicarios no es el de la primera fase de la modernidad que se veía como la del progreso; es el de la modernidad dañada por el exceso de ruido, de canales. Alexis, el joven sicario amante del narrador, es la encarnación de esa aceleración, es el ejemplo de esa cultura que anula cualquier tipo de experiencia. Aquí el cronotopo es Medallo-Metrallo, lleno de taxis estridentes, un Medellín urbano, relacionado con una ausencia de intimidad, correspondiéndose con la modernidad tardía. La referencia a Cuervo es una manera de demostrar la degradación y la contracara de la pretendida tradición lingüística, como parte de toda la tradición cultural perdida: del purismo que pretendía Colombia, o sus gramáticos, se ha desbarrancado hacia este argot incomprensible para cualquier extraño a las comunas.

Se producen, así, dos itinerarios narrativos que, al momento de confrontación de sus sujetos, establecen un intercambio, una transacción. De aquí surge un sujeto que resulta en una constante tensión entre dos mundos, entre dos cosmovisiones y en una reiterada lucha por no ser absorbido por aquella que rechaza y denosta; es decir, por la consecuencia de la distopía (¿o es la distopía misma?).

El allá que añora no puede fundirse sintéticamente en el aquí, pero, además, lo que realmente marca la diferencia es la visión del mundo del ayer que se opone a la de hoy y termina configurándose, en consecuencia, una oposición temporal también. En este sentido es que la antigua tierra de origen se nos aparece otra. Se fractura su vínculo de antaño con sus cosas y su medio, y establece otro tipo de relación. El deseo que se situaba al inicio del texto en la recuperación de un orden asentado en lo témporo-espacial, se convierte luego en el deseo afectivo o sexual y esto es lo que lo acerca al lugar de hoy, y hace que el discurso, monológico en un principio, entre en crisis y termine siendo casi lo contrario. Es así que le oiremos decir, primero “...me llegaban a los oídos pautadas por las infaltables delicadezas de 'malparido' e 'hijueputa' sin las cuales esta raza fina y sutil no puede abrir la boca" (92), 
para, finalmente, ver que integra el vocabulario sicario a su propio discurso: "Tenía que ir a esa iglesia a rogarle a Dios que todo lo sabe, que todo lo entiende, que todo lo puede, que me ayudara a matar a este hijueputa" (162).

Pero, tal como señala Raúl Bueno, no sólo el lenguaje de la cultura que lo enmarca se filtra en el sujeto migrante (2000:10), sino también "cuerpo, actitud, acciones, lengua, creencias y costumbres" (2000:10). Así, Fernando nos relata:

Sacó el Ángel Exterminador su espada de fuego, su “tote", su "fierro", su juguete, $y$ de un relámpago para cada uno en la frente lo fulminó. (...) “¿Qué pasó?” preguntó el desgraciado taxista viendo el tropel que se armaba afuera (...) "Nada" contesté- "Cuatro muertos. Y apague el loro que venimos supremamente ofuscados". Se lo dije en uno de esos tonos que he cogido que no admiten réplica, y dócil, sumiso, vil, lo apagó (78).

Si uno se pregunta quién es el lector interpelado en la obra, veremos que es un destinatario que el narrador preconcibe identificado en la denuncia, en el sobrevivir a la caótica realidad social finisecular. Sin embargo, en algún caso, ese sujeto interpelado también carga con la acusación del silencio, en cuanto el narrador siente que la nación se ha ido construyendo a través del consenso. Por eso en él se entabla una tensión que no logra resolver: aquella realidad social sobre la cual comienza ironizando, denunciando, condenando, y que es el motor de la escritura, termina casi absorbiéndolo en su sistema, aunque esto no signifique que la asuma sin contradicciones. La lucha entre lo que era y lo que va siendo es constante y reiterativa, y, como dice Raúl Bueno,

...su experiencia (la de migrante) entonces, se hace también cada vez más heterogénea en la medida en que absorbe los códigos y signos que le permitan ser funcional, con un mínimo posible de elaboraciones sobre su diferencialidad, en la nueva cultura. Deviene así un sujeto bicultural y, casi podríamos arriesgarnos a decir, bilingüe (...) Como resultado de ello sus sistemas de signos se transculturan, consciente o inconscientemente, al penetrar uno las formas del otro (2000:10).

Fernando, entonces, se configura como un sujeto en tensión con la heterogeneidad que no tenía internalizada y que, finalmente, termina convirtiéndolo en sujeto migrante en cuanto su discurso es descentrado, proliferante y desparramado: es, pues, un sujeto inestable, oscilante y plural (Raúl Bueno, 2000:9). Asume una doble pertenencia: aquí y allá, ahora y antes, pero de manera descentrada y conflictiva.

\subsection{Paraíso Travel ${ }^{15}$ : entre el sur periférico y el norte metropolitano}

El hecho de que te escriba en inglés ya falsea lo que quería contarte. Mi cometido: cómo explicarte que el inglés no es mi sitio aunque tampoco tengo ningún otro.

Gustavo Pérez Firmat

Una de las consecuencias de las violencias del último cuarto del siglo XX colombiano es el descalabro socioeconómico que repercute en las dificultades de un gran porcentaje de jóvenes para encontrar un futuro dentro del país. A esto le sumamos la implementación de políticas neoliberales que tanto desastre han hecho -y continúan haciendo-en América Latina, condenándola a una "modernidad periférica", sobre la que ya muchas páginas se han escrito.

Ante las escasas posibilidades frente a la privatización educativa, la poca o inexistente oferta

15 Todas las citas de la novela corresponden a la edición de Jorge Franco. Paraíso travel. Colombia: Seix Barral, 2001. 
laboral seria, entre otros factores, muchos son los que intentan la aventura de lograr el "sueño americano", para concluir, después de tremendas experiencias, que es sólo eso, un sueño.

La última novela de Jorge Franco, Paraíso Travel, nos da la posibilidad de encaminar nuestra mirada hacia esta situación. Pero además, nos muestra el proceso mismo de la lucha entre olvidar-recordar; asimilarse-rechazar, en su bipolaridad discursiva. Así, retomando a García Canclini, se nos amplía el espectro con relación a las modificaciones que se producen en la cartografía simbólica colombiana, como parte de esta problemática que, en realidad, abarca a toda América Latina y al Caribe. En tal caso, es bueno citar nuevamente al crítico argentino: "Quienes dejaron sus países, y ahora extienden nuestras culturas más allá de la región, muestran el desencaje doloroso de los latinoamericanos..." ( G. Canclini, 2002:12).

En Paraíso Travel se narra esta odisea a través de Marlon como paradigma de los migrantes indocumentados recién llegados a Estados Unidos. Torres-Saillant, escritor dominicano radicado en Nueva York, dice:

Sépase que la gente normalmente no abandona su tierra de manera voluntaria. Se desgaja de su cálido terruño, sus paisajes familiares, su lengua, su cultura y sus amores compelida por la urgencia material. Emigra quien no puede quedarse. Se van aquellos a quienes la economía nacional les ha cerrado las puertas. Aunque sus recursos analíticos no siempre les permitan discernir las fuerzas sociales que moldean su decisión de partir, los que se van realmente son expulsados: nuestra emigración es una expatriación (Torres, Saillant, 1999:39).

Podríamos preguntarnos si, atendiendo a lo que dicen tanto Torres-Saillant como Stuart Hall, no sería posible incorporar a Paraíso Travel dentro del corpus de la narrativa de la diáspora. "Las identidades de la diáspora son aquellas que están constantemente produciéndose y reproduciéndose de nuevo a través de la transformación y la diferencia", dice Stuart Hall (2003:484), estableciendo un punto de confluencia con la categoría de sujeto migrante desarrollada por Cornejo Polar. En la situación de diáspora, junto con la "conexión asociativa" (Hall, 2003:478) con el propio país, el de origen, se comparten, tal como vemos en Paraíso Travel, la "colombianidad" con otros migrantes.

Marlon se va "porque Colombia lo va dejando a uno sin argumentos..." (38). Sin embargo, la creciente heterogeneidad sociocultural en el territorio "invadido" será puesta en escena por la convivencia de usurpadores y usurpados, los intentos de negociación constantes, la mirada del otro marcando las diferencias que insertan a Marlon entre los estereotipos que naturalizan al latino con cargas disfóricas.

Al igual que en "Nadanostra" y en La Virgen de los sicarios, en Paraíso Travel se nos presenta al sujeto no después de la migración y ya instalado en su nuevo espacio, sino durante el proceso mismo, lo que nos permite vislumbrar la dinámica identitaria por la que va atravesando.

El presente de la enunciación nos muestra al migrante en la transitoriedad mental típica de la etapa inicial de la experiencia migratoria. “...finalmente termina uno padeciendo la maldición del emigrante: uno no se quiere quedar pero tampoco quiere volver" (145), dice Marlon. Así, de las primeras “ganas imparables de regresar" (20) ya que el olor le "obliga a cerrar los ojos", porque "el recuerdo le gana al aroma y aparecen de pronto el olor de mi casa, el olor a patio..." (20), el personaje pasará a un resignado "Tal vez uno termina olvidándose de volver" (145).

Pero este olvido a veces se torna un intento voluntario de ruptura con el lugar originario. La ambigüedad de sus sentimientos con respecto a él lo llevan a oscilar entre la nostalgia y el rechazo, al mismo tiempo que busca autoimponerse un arraigo en el nuevo espacio: "Yo que perdí mi ruta no he 
podido olvidar, por mucho que lo he intentado, lo que soy y de dónde he venido, no por renegar o por vergüenza, sino para poder empezar de cero, sin remordimientos y con los pies bien puestos sobre este lado de la tierra" (21).

El migrante ha ido creando una imagen del país al que esperaba llegar, de acuerdo con sus necesidades, y allí es donde se produce el primer choque. Las expectativas han hecho de esa tierra un mundo completo en cuanto a las búsquedas personales, pero la ilusión primera rápidamente se va desplazando hacia un sentimiento de frustración que profundiza el estar en la brecha que separa el allá del aquí: "Se van mermando las esperanzas, (...) uno comienza a ser desleal con sus sueños, se deja de llorar pero también de reír..." (145).

A veces, la nostalgia de lo propio se ve calmada en el encuentro con los compatriotas. En esta novela, se hace énfasis en lo que Raúl Bueno denomina "condición plural del sujeto migrante", en cuanto es un sujeto colectivo que "habla" como grupo. Esto se refuerza por la presencia, en el texto, del conjunto de inmigrantes colombianos. Las fiestas colectivas como para acercar la tierra se vuelven aún más exageradas en su homenaje y en el sentimiento que despiertan, quizás como una manera de retener un tiempo y un espacio que se mezclan con el símbolo o la representación de lo que dejaron. Ya muchos se reconocen como parte de un asentamiento permanente, como una minoría dentro de la población estadounidense. Ya despliega los atributos y los colores de una diáspora, sin obviar la autocrítica:

Aqui celebramos más fiestas que allá. $Y$ hasta más. ...los partidos de fútbol donde colombianos jugaban contra colombianos. Siempre nosotros contra nosotros mismos. ... Habia fritanga, música a todo volumen, mujeres con el ombligo afuera y mocosos hablando ya en inglés pero más parecidos a los que cuidan carros en Colombia que a los niños gringos (149).
Sin embargo, ese sentimiento nacional entra en tensión con un presente marcado por la fractura, al momento de la reflexión por las condiciones personales. "La circunstancia era para sentir dolor y rabia con una patria que no ofrece nada que no sea sangre y muertos y un futuro de pobreza" (178). Así, el sujeto que habla subraya su índole dispersa, $\mathrm{y}$, como consecuencia, surge la autoconciencia degradante. La novela está cargada de reflexiones semantizadas disfóricamente con respecto al "ser colombiano". Con frases como las siguientes, se ontologiza a un sujeto, se naturaliza una condición que es puramente cultural, y establece, además, una visión del mundo cerrada: "No se puede ser colombiano por fuera de Colombia" (195). "Aquí un colombiano puede conseguir mucha plata si le saca provecho a la reputación" (207). La novela narrativiza el sentir "ser colombiano" como un estigma que hiere no sólo en la relación con los otros, sino con uno mismo, con la propia identidad. Así, este sujeto migrante huye de sí mismo de alguna manera, porque es dentro de sí mismo que se dan el rechazo y el deseo.

Otra vez, entonces, la mirada del otro en la constitución del migrante. Pero la mirada de ese otro, dueño del espacio invadido, no termina en la observación de aquél como lo raro, sino que va cargado de un juicio de valor en tanto inferiorizante y lleno de sospechas. Así, el olor real, concreto, al que tantas veces refiere Marlon con respecto a sí mismo, se desdibuja o se desdobla en el olor simbólico ante lo distinto, lo desconocido, aquello de lo cual lo único que se sabe es que es un desplazado, un migrante, otro extraño, y en función de ello se actúa: "En una ciudad donde se ve de todo, donde la curiosidad no existe, nadie mira más que por donde van sus pasos, pero todos los que estuvieron allí nos observaron, porque tal vez muy pocos habían visto al que tuvo el privilegio de ascender de los infiernos" (54).

La tensa convivencia con la sociedad receptora agudiza la memoria de la tierra natal, memoria que se alimenta con el resentimiento de haber sido ex- 
pulsados del suelo patrio. En medio de este estar a caballo entre dos culturas es que comienza el juego de negociaciones para la sobrevivencia. "Necesidad" es, sin duda, el término que el sujeto acuña con mayor frecuencia. Necesidad de fagocitarse con los nuevos espacios y culturas. Como dice Marlon un tiempo después de llegado: "No podría decir que me fui habituando a vivir en Nueva York; me resigné, que es muy distinto, y como un parásito aprendí a habitar en sus entrañas y a comer de ellas, siempre atento para no provocar a la bestia" (146).

Es claro, entonces, que en la situación de descentramiento del personaje, expuesto a una situación de desarraigo, asume los nuevos ejes culturales como necesarios recursos de vida. Todo esto, atravesado por una cultura otra que marca la ajenidad a partir del lenguaje mismo, y al que se debe lograr dominar, situación que provoca una fractura no sólo en la cotidianidad de las prácticas sociales, sino en la identidad del sujeto que debe aprender a pensar en otro idioma. Marlon, después de un año, logra aprender inglés "a las patadas", por lo que sólo puede "relacionar este idioma con la necesidad". Esto implica que la diversidad cultural impone un límite y rompe con la fantasía de la plenitud. Si bien el personaje irá consiguiendo espacios que lo acercarán a una sensación de triunfo, ésta no será nunca completa.

Al iniciar la novela, Marlon, todavía en Medellín, ante la duda que le provocaba el viaje, pensaba “... yo soy muy de acá. Tan de acá que no me quiero ir"(12). Luego, y como ya lo señalamos, termina olvidándose de volver. Emigrar es, sin duda, como dijo un exiliado, estar apoyado sobre dos témpanos en alta mar, sin lograr poner las dos piernas en uno solo.

Creo que desde la literatura todavía no se ha logrado dar cuenta cabal -al menos en lo que se refiere a los movilizados dentro de las fronteras nacionales-del resquebrajamiento cultural que el desplazamiento les impone. Y me pregunto si eso no será un síntoma de que, aunque sea desde el ámbito literario, no se ha aprehendido de manera absolutamente consciente la problemática de esta "cultura trashumante" a la que se obliga a los desplazados.

Probablemente estas circunstancias, por lo repetidas, se tornan normales a la conciencia social. Lo reiterativo produce un efecto anestésico, y de allí a la invisibilización hay sólo un paso. No en vano la proliferación de institucionales televisivos en los que se insiste en que "todo nos une con el desplazado: la misma, bandera, el mismo suelo, etc.”. Pero esos elementos que conforman la "comunidad imaginada" no son suficientes para que el desplazado sienta que al verse obligado a la desterritorialización, su acogida en cualquier otro lugar del país sea sólo un cambio de lugar, lo que ya de por sí es fracturante para sus vidas.

Tanto las víctimas del desplazamiento forzado, como las exiliadas voluntarias, aunque no por eso menos victimizadas en el doble movimiento que implica la dinámica de la migración, desterritorialización, reterritorialización, delatan en sus discursos su ubicación en mundos opuestos y la existencia de puntos de contacto y negociaciones, conscientes o no, como única medida de sobrevivencia.

Una posibilidad de elaboración del sentimiento de "no pertenencia", del desarraigo, sería lograr resignificar y contextualizar los referentes anteriores, los del lugar de origen, junto a la incorporación de las nuevas significaciones. Sin embargo, todos los sujetos exteriorizan su doble inscripción en mundos disímiles, uno de los cuales aparentemente ha desaparecido, para dejar lugar al discurso del presente. En cualquier caso, éste resulta dicente de la coexistencia de dos mundos antagónicos en la conformación interna de los sujetos, que, insisto, la literatura debería remarcar sin que esto se convierta en un juego pintoresco, sino descubriendo, desde lo estético, esa terrible realidad. 


\section{Bibliografía}

AA.VV. (2002). Éxodo, patrimonio e identidad. Bogotá: Universidad Nacional de Colombia.

ALTUNA, E. (1998). “Territorios de la memoria. El ‘sujeto migrante' en el relato de viaje colonial”, en Kipus: Revista andina de literatura, $\mathrm{N}^{\circ}$ 9, II semestre,17-27.

ARGUMEDO, Alcira (2002). Los silencios y las voces en América Latina. Buenos Aires: Ediciones del pensamiento nacional.

BUENO, R. (1996). "Sobre la heterogeneidad cultural y literaria de América Latina”, en Mazotti, J. A. y U. J. Zevallos Aguilar (Coord.), Asedios a la heterogeneidad cultural. Libro de homenaje a Antonio Cornejo Polar. Philadelphia: Asociación Internacional de Peruanistas, 26-36.

(1998). "Heterogeneidad migrante y crisis del modelo radial de cultura", en Moraña, Mabel (Ed.), Indigenismo hacia el fin de milenio. Homenaje a Antonio Cornejo Polar. Pittsburg: Instituto Internacional de Literatura Iberoamericana, serie Biblioteca de América, 253-268.

(2000). Carta a JALLA-Cuzco: Indagaciones conceptuales sobre cultura y literatura. Hannover, N.H.

(2002). "Sujeto heterogéneo y migrante. Constitución de una categoría de estudios culturales", en Schmidt-Welle, Friedhelm (Ed.), Antonio Cornejo Polar y los estudios latinoamericanos. Pittsburgh/Berlín: Instituto Internacional de Literatura Iberoamericana e Ibero-Amerikaniskes Institut, 173-194.

BURGOS Cantor, Roberto (2001). "NADANOSTRA”, en Lugares ajenos. Relatos del desplazamiento. Medellín: Fondo Editorial Universidad Eafit, Colección Antorcha y Daga.

CORNEJO POLAR, A. (1994). "Condición migrante e intertextualidad multicultural: el caso de Arguedas", en Revista de Crítica Literaria Latinoamericana, 42:XXI 101-109.

(1996). "Una heterogeneidad no dialéctica: sujeto y discursos migrantes en el Perú Moderno", en Revista Iberoamericana. Vol. LXII, No. 176-177, 837-844.

(1994). Escribir en el aire. Lima: Ed. Horizonte.

(1977). "Problemas de la crítica, hoy". Texto crítico 6, Veracruz, enero-abril.

(1993). "Ensayo sobre el sujeto y la representación en la literatura latinoamericana: algunas hipótesis", en Hispamérica: Revista de Literatura Hispanoamericana. Gaithersburg, MD., Vol 22. No. 66, 3-15.

FRANCO, Jorge (2001). Paraíso travel. Colombia: Seix Barral.

GARCÍA CANCLINI, Néstor (2002). Latinoamericanos buscando lugar en este siglo. Buenos Aires: Paidós.

GARCÍA DURÁN, M. (1999). “Los desplazados por la violencia en Colombia. Con su dolor sin rumbo”, en Universitas Humanística, 47: XXVII, 15-31.

GIRALDO, L. M. (2002). “Escrituras del desplazamiento en la narrativa colombiana”, en Palimpsesto, 2. 38-43.

(2002). "Inmigrantes y desplazados en la narrativa colombiana contemporánea", en Universitas Humanistica,53:XXIX, 13-31.

HALL, Stuart (2001). "Identidad cultural y diáspora”, en Von der Walde, Erna (Comp.), Miradas anglosajonas al debate sobre nación. Cuadernos de nación. Bogotá: Ministerio de Cultura.

(2003). "Pensando en la diáspora: en casa desde el extranjero", en A. Jáuregui y Juan Pablo Dabove (Ed.), Heterotropias: narrativas de identidad y alteridad latinoamericana. Pittsburgh: Biblioteca de América, 477-500.

KUSCH, Rodolfo (1976). Geocultura del hombre americano. Buenos Aires: F. García Cambeiro.

LÓPEZ MAGUIÑA, Santiago (2003). “El concepto de discurso heterogéneo en la obra de Antonio Cornejo Polar”, en Heterogeneidad y Literatura en el Perú. Lima: Celap.

MAZZOTTI y ZEVALLOS (coord.) (1996). Asedios a la heterogeneidad cultural. Libro en homenaje a A. Cornejo Polar. Philadelphia: Asociación Internacional de Peruanistas. 
MOLANO, ALFREDO (2001). Desterrados. Colombia: el Áncora Editores.

PALERMO, Z. (2002). "Para una descolonización del conocimiento. Cornejo Polar y la noción de "totalidad contradictoria"”, en Silabario, No.5, Vol. 5, 35-46.

RAMA, Ángel (1986). "Los procesos de transculturación en la narrativa latinoamericana”, en La novela en América Latina. Panoramas 1920-1980. Uruguay: Fundación Ángel Rama.

TORRES-SAILLANT, Silvio (1999). El retorno de las yolas. Ensayos sobre diáspora, democracia y dominicanidad. República Dominicana: Editora Manatí.

SÁNCHEZ R. y JARAMILLO L. (1999) “Impacto del desplazamientos obre la salud mental”, en Universitas Humanística, 47:XXVII, 88-101.

VALLEJO, Fernando (1994). La virgen de los sicarios. Bogotá: Alfaguara.

Artículo recibido el 15 de abril de 2004 y aprobado el 9 de diciembre de 2004 